$$
\begin{aligned}
& \text { CONF-961110--20 } \\
& \text { ANL/TD/CP--91825 } \\
& \text { RECEIVED }
\end{aligned}
$$

IAN 16 G 9997

O S T I

\title{
DESIGN STUDIES FOR A HIGH-RESOLUTION, TRANSPORTABLE NEUTRON RADIOGRAPHY/RADIOSCOPY SYSTEM
}

\author{
George H. Gillespie \\ G. H. Gillespie Associates, Inc. \\ P. O. Box 2961 \\ Del Mar, California 92014, U.S.A. \\ Bradley J. Micklich and Gerry E. McMichael \\ Argonne National Laboratory \\ 9700 S. Cass Ave. \\ Argonne, IL 60439, USA
}

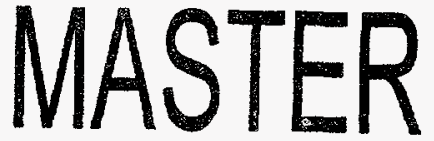

30 September 1996

This paper is being submitted for publication in the Proceedings of the

Fourteenth International Conference on the Application of Accelerators in Research and Industry held November 6-9, 1996 in Denton, Texas 


\section{DISCLAIMER}

Portions of this document may be illegible in electronic image products. Images are produced from the best available original document. 


\title{
DESIGN STUDIES FOR A HIGH-RESOLUTION, TRANSPORTABLE NEUTRON RADIOGRAPHY/RADIOSCOPY SYSTEM
}

\author{
George H. Gillespie ${ }^{a}$, Bradley J. Micklich ${ }^{b}$ and Gerry E. McMichael \\ ${ }^{a}$ G. H. Gillespie Associates, Inc., P.O. Box 2961, Del Mar, CA 92014, U.S.A. \\ ${ }^{b}$ Argonne National Laboratory, 9700 S. Cass Ave., Argonne, IL 60439, USA
}

\begin{abstract}
A preliminary design has been developed for a high-resolution, transportable neutron radiology system (TNRS) concept. The primary system requirement is taken to be a thermal neutron flux of $106 \mathrm{n} /\left(\mathrm{cm}^{2}-\mathrm{sec}\right)$ with a $L / D$ ratio of 100 . The approach is to use an accelerator-driven neutron source, with a radiofrequency quadrupole (RFQ) as the primary accelerator component. Initial concepts for all of the major components of the system have been developed, and selected key parts have been examined further. An overview of the system design is presented, together with brief summaries of the concepts for the ion source, low energy beam transport (LEBT), RFQ, high energy beam transport (HEBT), target, moderator, collimator, image collection, power, cooling, vacuum, structure, robotics, control system, data analysis, transport vehicle, and site support. The use of trade studies for optimizing the TNRS concept are also described.
\end{abstract}

\section{INTRODUCTION}

Neutron radiography and radioscopy (NR) have been used for a number of applications, including the examination of airframe parts, turbine blades, nuclear fuel components, and many research specimens in a variety of fields (1). Two key parameters are used in describing NR systems: (a) the thermal neutron flux, $\Phi$, incident upon the inspection specimen and (b) the divergence of the thermal neutron beam. NR beam divergence is traditionally characterized by the ratio $L / D$, where $L$ is the distance from the thermal neutron source to the specimen location, and $D$ is the effective diameter of the thermal neutron beam at the source location. Reactor-based facilities provide intense, high-resolution thermal neutron beams, with $\Phi$ of 106 $\mathrm{n} /\left(\mathrm{cm}^{2}-\mathrm{sec}\right)$ or more, and $L / D$ ratios of 100 or more. Mobile or transportable NR systems with similar performance would find applications in many areas.
This paper describes the preliminary conceptual design for a transportable neutron radiography/radioscopy system (TNRS), based upon an accelerator-driven neutron source, capable of producing a thermal neutron flux of $10^{6} \mathrm{n} /\left(\mathrm{cm}^{2}-\right.$ sec) with a $L / D$ of 100 . Figure 1 illustrates the basic concept of an accelerator-driven NR facility. The product $(L / D)^{2} \Phi$ is a measure of the thermal neutron source strength (a constant for a point source) and provides a figure of merit that may be used to compare different NR systems. Transportable or mobile NR systems based on radioactive sources (2), D-T tubes (3), cyclotrons (4) and pulsed linear accelerators (5) have been developed that provide values of $(L / D)^{2} \Phi \sim 10^{9} \mathrm{n} /\left(\mathrm{cm}^{2}-\mathrm{sec}\right)$. The use of a continuous wave (CW) radiofrequencyquadrupole ( $R F Q$ ) accelerator $(6)$ as the NR driver offers the possibility of increasing this figure of merit by an order of magnitude, making feasible a transportable system with reactor-grade performance.

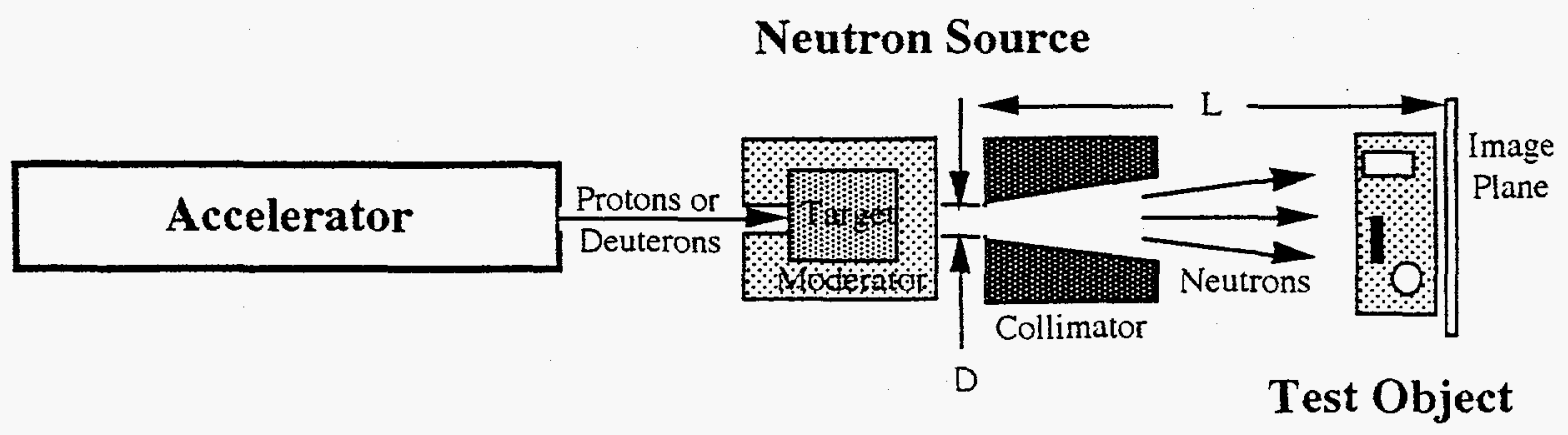

FIGURE 1. Accelerator-based neutron radiography/radioscopy (NR). 
TABLE 1. Subsystems and major assemblies of the TNRS concept.

\begin{tabular}{|c|c|c|c|}
\hline Subsystem (WBS ID) & Assemblies (WBS ID) & Subsystem (WBS ID) & Assemblies (WBS ID) \\
\hline Injector $(1000)$ & $\begin{array}{l}\text { Ion Source }(1100) \\
\text { LEBT }(1500) \\
\text { Vacuum }(1700) \\
\text { Cooling }(1800)\end{array}$ & $\begin{array}{l}\text { Instrumentation \& Controls } \\
\quad(5000) \\
\text { Structure \& Robotics } \\
\quad(6000)\end{array}$ & $\begin{array}{l}\text { Control System }(5100) \\
\text { Diagnostics }(5300) \\
\text { Primary Support }(6100) \\
\text { C-Support }(6300)\end{array}$ \\
\hline RFQ (2000) & $\begin{array}{l}\text { RFQ }(2100) \\
\text { RF Coupling (2300) } \\
\text { Vacuum }(2700)\end{array}$ & Transportation $(7000)$ & $\begin{array}{l}\text { Robotic Table }(6500) \\
\text { TNRS Vehicle }(7100) \\
\text { Controls Van }(7500)\end{array}$ \\
\hline Neutron Production & $\begin{array}{l}\text { Cooling (2800) } \\
\text { Target, Moderator \& Collimator }(3100)\end{array}$ & Site Support $(8000)$ & $\begin{array}{l}\text { Site Support }(8100) \\
\text { Ltility Interfaces }(8500)\end{array}$ \\
\hline$(3000)$ & $\begin{array}{l}\text { HEBT }(3500) \\
\text { Vacuum }(3700) \\
\text { Cooling }(3800)\end{array}$ & $\begin{array}{l}\text { Radiofrequency Power } \\
\qquad(9000)\end{array}$ & $\begin{array}{l}\text { Amplifier }(9400) \\
\text { Circulator }(9500) \\
\text { Distribution }(9600)\end{array}$ \\
\hline $\begin{array}{l}\text { Radiograph Production } \\
\qquad(+000)\end{array}$ & $\begin{array}{l}\text { Image Capture }(4100) \\
\text { Image Analysis \& Archiving }(4300)\end{array}$ & & $\begin{array}{l}\text { Drive \& Controls }(9700 \\
\text { Cooling }(9800)\end{array}$ \\
\hline
\end{tabular}

\section{TNRS CONCEPT OVERVIEW}

The TNRS is envisioned to be a self-contained, trailermounted device that would be transported to user sites for extended operations $(7,8)$. The overall system has been divided into nine major subsystems Each subsystem has been further defined by identifying its major assemblies. One goal of the design effort was to provide a description of the TNRS similar to that found in the first two levels of detail in a typical industrial work breakdown structure (WBS). Table 1 summarizes the subsystems and major assemblies. The WBS identification (ID) numbers given in Table $I$ are used for bookkeeping purposes, principally in the generation of parts lists and cost estimates in system studies. The design provides for a compact ( 24 foot long) configuration during transport, with deployable neutron production and radiographic imaging assemblies. A side view illustration of the TNRS concept in the deployed configuration is given in reference 7 .

\section{ACCELERATOR SUBSYSTEMS}

The accelerator for the TNRS is composed of the injector subsystem and the RFQ subsystem, which are illustrated in Figure 2. The injector subsystem consists of four major assemblies: (a) an electron cyclotron resonance (ECR) positive hydrogen ion $\left(\mathrm{H}^{+}\right)$source assembly and power supplies, (b) a dual solenoid low energy beam transport (LEBT) system, (c) a vacuum pump system, and (d) a deionized water system with interfaces for utility water to supply cooling for the ion source and solenoids. The ion source and solenoids are similar to those used previously at Chalk River (9) and Los Alamos (10). The ECR source is capable of delivering high quality proton beams with very low molecular content (11). At the design extraction energy of $50 \mathrm{keV}$, the injector can produce a continuous beam of over $75 \mathrm{~mA}$, considerably more than required by the TNRS.

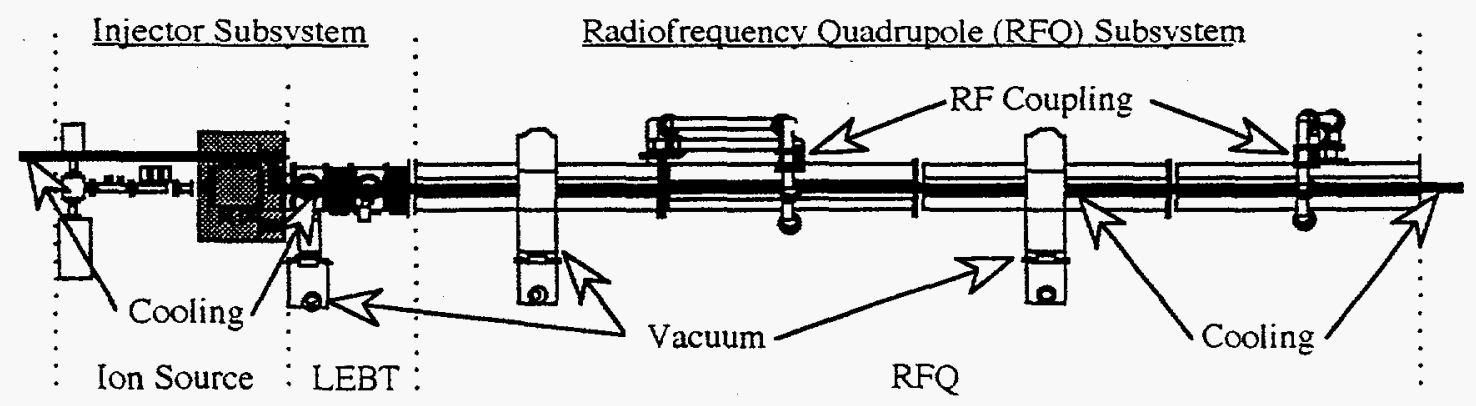

FIGURE 2. Accelerator subsystems and assemblies for the transportable NR system, at 1/30 scale. 
The RFQ subsystem includes: (a) a four segment vane-type $R F Q$, (b) eight radiof requency (RF) power drive loop assemblies with four loops each located at the second and fourth segments, (c) two vacuum manifold pump stations, one each at the first and third segments, and (d) a coolant manifold to supply water to the RFQ. Parameters for the RFQ and the results of computer performance simulations are given in reference8. The RFQ is similar to designs developed for the front end of a CW accelerator for the production of tritium (12), although the TNRS RFQ is designed for lower energy and somewhat lower current.

\section{RADIOGRAPHY/RADIOSCOPY SUBSYSTEMS}

The radiological subsystems are illustrated in Fig. 3 and include neutron production and neutron imaging. The neutron production subsystem is comprised of four primary assemblies: (a) a beryllium neutron target, polyethylene moderator and cadmium lined collimator, (b) a high energy beam transport (HEBT) line with a quadrupole triplet to transport and focus the proton beam onto the target, (c) a vacuum station, and (d) a cooling system. The neutron imaging subsystem supports both electronic (radioscopy) and film (radiography) imaging and is comprised of two primary parts: (a) an image capture assembly with photographic and TV imaging capabilities, and (b) a data analysis and archiving laboratory, which would be located in the instrumentation and controls van.

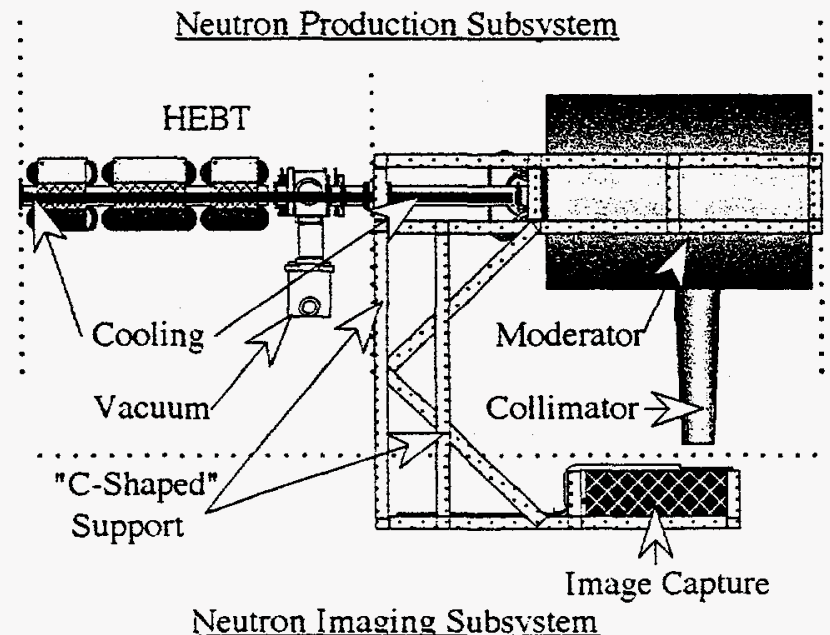

FIGURE 3. Radiological subsystems and assemblies for the transportable NR system, at 1/30 scale. The neutron production target is located inside the moderator; the photographic and TV components are located inside the image capture assembly.

Target, moderator and collimator performance impact the optimum choice for the proton beam energy and current. Analytic parameterizations for the neutron yields and thermalization factors as a function of beam energy and current, useful in carrying out system-level trade studies, were described in previous work (8). Those studies utilized a light water moderator design (13) which has a lower thermalization efficiency than is possible with polyethylene moderators $(4,5)$. In this work, maximum thermalization efficiencies were computed for polyethylene and are given in Table 2. Estimates of the achievable efficiencies for practical moderators were made from the data in (4) and (5).

TABLE 2. Thermalization limits for polyethylene.

\begin{tabular}{ccc}
\hline \hline Neutron Energy, $E_{n}$ & Efficiency, $\eta_{t h}$ & Neutron Source \\
\hline 0.354 & $3.27 \times 10^{-2}$ & $\mathrm{Li}(\mathrm{p}, \mathrm{n}) @ 2.5 \mathrm{MeV}$ \\
0.851 & $2.42 \times 10^{-2}$ & $\mathrm{Be}(\mathrm{p}, \mathrm{n}) @ 3.5 \mathrm{MeV}$ \\
1.06 & $2.21 \times 10^{-2}$ & $\mathrm{Be}(\mathrm{p}, \mathrm{n}) @ 4.0 \mathrm{MeV}$ \\
1.99 & $2.13 \times 10^{-2}$ & $\mathrm{AcBe}$ \\
2.31 & $1.62 \times 10^{-2}$ & $\mathrm{Cf} 252$ \\
2.45 & $1.13 \times 10^{-2}$ & $\mathrm{~d}(\mathrm{~d}, \mathrm{n})$ \\
4.29 & $1.07 \times 10^{-2}$ & $\mathrm{AmBe}$ \\
14.0 & $2.69 \times 10^{-3}$ & $\mathrm{t}(\mathrm{d}, \mathrm{n})$ \\
\hline
\end{tabular}

The polyethylene thermalization efficiencies for average neutron energies of $0.2-2.0 \mathrm{MeV}$ are parameterized by:

$$
\eta_{t h}\left(\mathrm{~cm}^{-2}\right)=a\left(E_{n}\right)^{-b},
$$

with $b=0.44$ and $a=0.022$ for the maximum (upper line) efficiency, while $b=0.67$ and $a=0.012$ for the estimated practical efficiency. Figure 4 summarizes these results and compares them to light water moderator parameterizations.

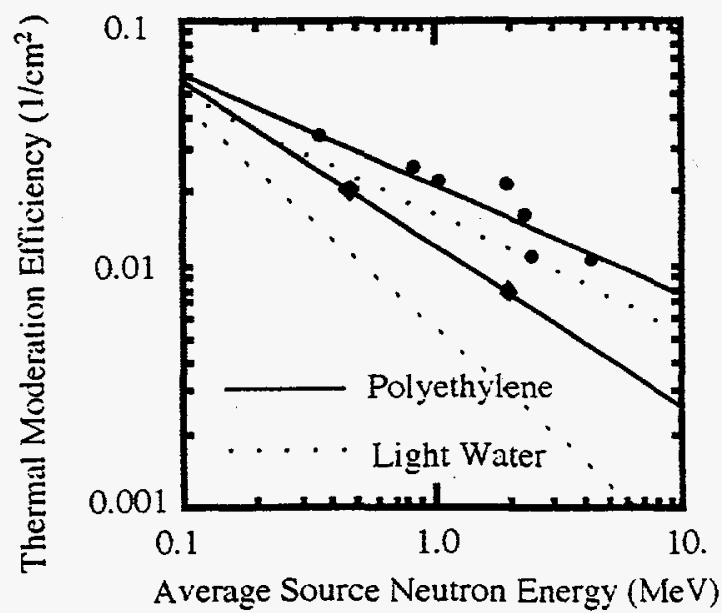

FIGURE 4. Parameterization of the thermalization efficiency for polyethylene moderators (solid lines). Circles are for the calculations of Table 2 and diamonds are estimated values from references $(4,5)$. Dotted lines show parameterizations for light water moderators (8). 


\section{OTHER SUBSYSTEMS}

Other subsystems include those for the structure and robotics, transportation, and RF power. The structure and robotics subsystem provides (a) a space frame for the structural support of the accelerator, (b) a detachable "Cshaped" support frame illustrated in Fig. 3 for the target/moderator/collimator and image capture assemblies, and (c) a remotely controlled two-axis translation table that permits scanning over a $1 \mathrm{~m}^{2}$ area. The transportation subsystem consists of two trailer vehicles: (a) the NR system vehicle and (b) an instrumentation and control (I\&C) van. Personnel operate the TNRS from the $I \& C$ van.

\section{TRADE STUDIES}

Trade studies, using the Accelerator Systems Model (ASM) computer code originally developed for studying high-energy linear accelerator systems (14), have been initiated to further optimize the system. ASM provides existing detailedmodels for the injector, RFQ and RF power subsystems, as well as user definable modules for modeling other subsystems and assemblies. A neutron production subsystem model has been developed for ASM, using the target/moderator/parameterizations described here and in previous work, together with existing ASM HEBT models. Results obtained to date show that a $100 \%$ duty factor (i.e. $\mathrm{CW}$ ) proton beam energy of about $3.5 \mathrm{MeV}$ can generate a thermal neutron flux of $10^{6} \mathrm{n} /\left(\mathrm{cm}^{2}-\mathrm{sec}\right)$, at a L/D of 100 , with considerably less current than $30 \mathrm{~mA}$. The total power requirement for the system is less than $500 \mathrm{~kW}$. The RF power can be supplied by one or two high-efficiency amplifiers operating at $350 \mathrm{MHz}$. The dimensions and weight of the TNRS will permit it to be transported on a modest sized ( 24 foot) trailer.

\section{ACKNOWLEDGEMENTS}

This work was completed under the auspices of the U. S. Department of Energy under contract W-31-109-ENG-38 and Argonne National Laboratory subcontract 961002402 .

\section{REFERENCES}

1. Barton, J. P., editor, Neutron Radiography (4) Including Radioscopy and Complementary Inspection Methods Using Neutrons, Proceedings of the Fourth World Conference, New York, Gordon and Breach, 878 pages (1993).

2. Orphan, V., Kedem, D., and Johansen, F., "Mobile Neutron Radiography System for Aircraft Inspection," in Neutron Radiography, Proceedings of the Second World Conference, The Netherlands, D. Reidel, $47++54$ (1987).

3. Cluzeau, S., Huet, J., Huriet, J. R., and Le Tourneur, P., Nucl. Instr. Meth. Phys. Res. B 79, 852-85+ (1993).
4. Allen, D. A., Hawkesworth. W. R., Beynon, T. D., Green, S., Rogers, J. D., Allen, M. J., Plummer, H. C., Boulding, N. J., Cux, M., and McDougall, I.. Nucl. Instr. Meth. Phys. Res. A 353, 128-133 (1994).

5. Hamm, R. W., "Status of the LANSAR ${ }^{\mathrm{rM}}$ Neutron Generators," presented at the Fifth World Conference on Neutron Radiography, June 17-20, 1996, Berlin, Germany.

6. Arbique, G. M., Chidley, B. G., Mc.lichael, G. E., and Sheikh, J. Y., "Beam Parameter Measurements on the CW RFQ1-1250 Accelerator," 1992 Linear Accelerator Conference Proceedings, AECL-10728, 55-57 (1992).

7. Gillespie, G. H., Mc.lichael, G. E. and Imel, G. R., "Concept design of a transportable, high-resolution, neutron radiography system," presented at the 5th International Conference on Applications of Neutron Techniques, June 9-15, 1996, Crete, Greece

8. Gillespie, G. H., Mc.Michael, G. E., Micklich, B. J., and Imel, G. R., "RFQ-Based, Transportable, HighResolution Neutron Radiography System Concept," presented at the Fifth World Conference on Neutron Radiography, June 17-20, 1996, Berlin, Germany.

9. Tavlor, T., and Wills, J. S., "Enhanced High-Current ECR Proton Source," 1992 Linear Accelerator Conference Proceedings, AECL-10728, Vol. 1, 350-352 (1993).

10. Stevens, R. R., Schafstall, P., Schneider, J. D., Sherman, J., Zaugg, T., and Taylor, T., "DC Proton Beam Measurements in a Single-Solenoid Low-Energy Beam Transport System," Proceedings of the 1994 International Linac Conference 2, 549-551 (1994).

11. Spence, D., Lykke, K. R., and McMichael, G. E., "Plasma Modified Production of High-current, High-purity $\mathrm{CW} \mathrm{H}^{+}$, $\mathrm{D}^{+}$, and $\mathrm{H}^{-}$Beams from Microwave-driven Sources," presented at the 18th International Linac Conference, August 26-30, 1996, Geneva, Switzerland.

12. Schrage, D., Roybal, P., Young, L, Clark, W., DePaula, R., and Martinez, F., "A New RFQ Linac Fabrication Technique," Proceedings of the 1994 international Linac Conference 1, 152-154 (1994).

13. Imel, G. R., Singleterry, R. C. Jr., Gillespie, G. H., and McMichael, G. E., Nucl. Instr. Meth. Phys. Res. A 377 , 20-22 (1996).

14. Paulson, C. C. Todd, A. M. M., Peacock, M. A., Reusch, M. F. Bruhwiler, D., Mendelsohn, S., Berwald, D., Piaszczyk, C., Mevers, T., Gillespie, G. H., Hill, B. W. and Jameson, R. A., "Accelerator Systems Optimizing Code," Proceedings of the 1995 Particle Accelerator Conference 1, 1164-1166 (1995) 